\title{
Ahmadi Redevelopment Projects: Power Generating Pavements
}

\author{
Ahmed Khalil
}

\begin{abstract}
The ever-increasing energy demands of today's rapidly emerging world economies, has placed energy use and conservation at the heart of the world sustainability challenge. Consequently, a lot of focus and research is aimed at the implementation of the various sustainable strategies and models, to address the global sustainability challenges in energy use and its conservation. This paper presents an overview of an approach considered to meet this global sustainability challenge by Ahmadi Sports Ground, which is considered as one of the masterpieces of Ahmadi Township, developed by the Kuwait Oil Company (KOC).

The paper introduces the specific application of using energy generating tiles through energy harvesters in the Ahmadi Sports Ground. For a good comprehension, the paper takes the elementary materials scientific development from their history and mentions the actual acknowledgement and energy generation mechanism of those materials throughout concurrent researches.
\end{abstract}

Index Terms-Harvest, nano generator pavements, piezoelectric, renewable energy, smart.

\section{INTRODUCTION}

As countries around the world are striving to address the various global sustainability challenges, organizations and professionals around the world are under much pressure to invent alternative energy sources that are less expensive and renewable, for a sustainable future. In the recent past, we can see that many countries have developed their visions to reduce energy usage and increase energy supply from renewables. Ahmadi Town is one of the most important suburbs of Kuwait City, located $40 \mathrm{~km}$ southeast of the Kuwait City center and is spread over an area of 5.12 sq. $\mathrm{km}$. The township of Ahmadi was developed in 1946 by the Kuwait Oil Company, to accommodate various amenities like recreational facilities, shopping areas, banks, cinemas...etc., in addition to catering to the housing needs of its employees.

The Sports Ground is one of the major parts of the Ahmadi Township, which was developed to create a location in Ahmadi for recreational activities and multipurpose play fields for all ages for a healthy and happy lifestyle, and thereby promote the to the housing needs of its employees. The Sports Ground is one of the major parts of the Ahmadi Township, which was developed to create a location in Ahmadi for recreational activities and multipurpose play fields for all ages for a healthy and happy lifestyle, and thereby promote the growth of a vibrant and prosperous

Manuscript received April 18, 2019; revised November 12, 2019.

Ahmed Khalil was with Ain Shams University of Egypt, Egypt. He is now with Kuwait Oil Company, Ahmadi, Kuwait (e-mail: AKhalil@kockw.com).
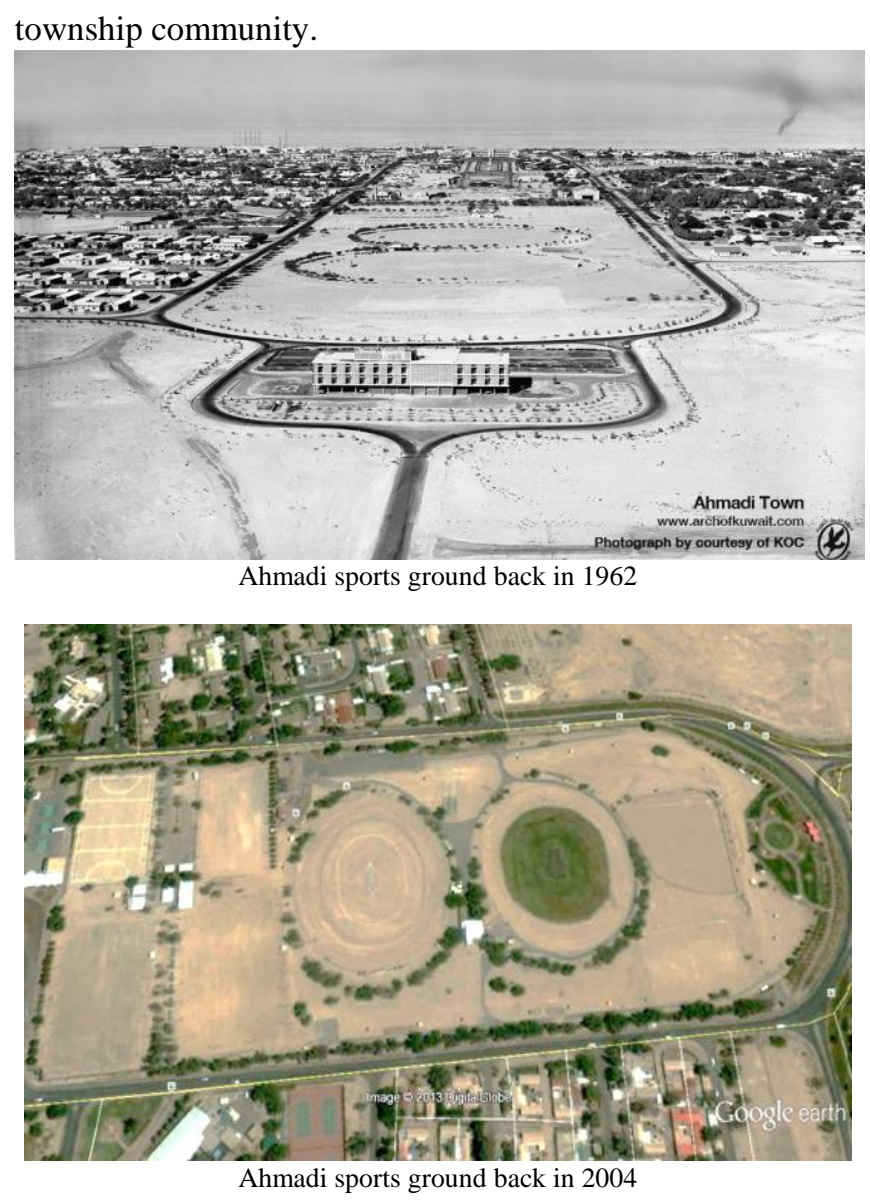

As years progressed, it was found that the condition of the sports ground was in poor condition, which decreased its usefulness and function, affecting the image of the Company. Therefore a major upgradation and enhancement of the sports ground was planned and the project commenced on 2012. Kuwait Oil Company has been committed to extend its support in all its endeavors and serve as a vital platform to show case and set a positive precedent in the region for the comprehensive sustainable and inclusive growth by adopting strategic, technical and technological solutions for energy efficiency and power generation etc. in its projects.

The Company's vision and strategic objectives are outlined to support Kuwait's 2030 energy vision to reduce energy usage per capita and increase the energy supply from renewables to $15 \%$ and formulate strategies, discuss the latest case studies and benchmark against global best practices.

Based on this strategic vision, the design and construction of the sports ground was carefully planned to suit the Company's objectives, and promote exercise, jogging, roller blading, skate boarding, cricket, football etc.... This paper illustrates the specific application of using energy generating tiles through energy harvesters in the Ahmadi Sports Ground. 


\section{LITERATURE REVIEW}

In today's world, sophisticated sciences like electromechanical, mechatronics, and physico-chemistry tackle renewable energy sources through material Research \& Improvement studies in an elementary scale.

\section{A. Early (Short) History}

The first discovery of such materials was "pyroelectric" materials, defined by Linnaeus and Franz Aepinus, in mid- $18^{\text {th }}$ century [1]. Pyroelectric effect means " Generation of an electric potential in response to a temperature change on material and its molecules".

Sequentially, "piezoelectric" materials and piezoelectric effect came to the scene, in 1880 by the discovery of Pierre Curie and Jack Curry, also called Curie Brothers [1]. Piezoelectric effect means, " Electrical energy generation in material structure, due to a mechanical condition change by bending, pressing, squeezing and/or stretching."

In 1881, Gabriel Lippmann discovered the converse piezoelectricity, and proved it with a mathematical formula [1]. Converse piezoelectricity effect means, "Condition and/or shape change due to electrical impact on the material". This is the reverse behavior of piezo electricity.

In above historical spectrum, we have no evidence proving that whether there was objective on renewable energy sourcing or not. However, piezoelectric materials and their types were used in devices and equipments from ultrasound technologies to our credit card chips; not only for energy generation, but also for information transfer, visualization, automation etc...[2], [3]

There are various institutions and corporations that Research \& Improve different formations, manufacturing technologies; from universities, science associations and private sector manufacturer firms. Unfortunately, we didn't recognize the existence of a centralized corporation which collects all data from all these researches with a total approach. Therefore, this R\&I process is driven mostly by individual initiatives.

It would be useful to have a look at elementary process of energy generation, through the molecules of piezoelectric and pyroelectric materials, as presented below:

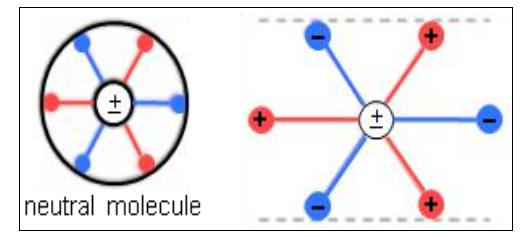

Fig. 1. A crystal molecule in neutral condition without any external effect. Negative and positive charges of the molecule coincide physically in the center. [3]

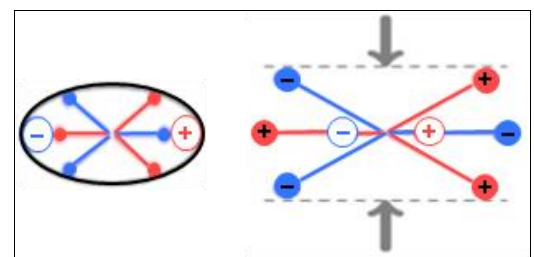

Fig. 2. The crystal molecule after applying an external press effect on the molecule. Internal structure of molecule is deformed. Such deformation causes separation of positive and negative centers, shown in blue and red circles. [3]

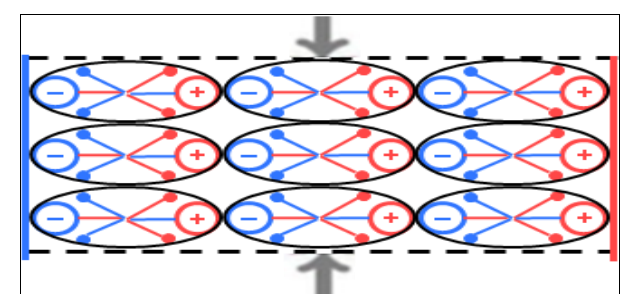

Fig. 3. The group of small dipole molecules which is the piece of visible material by us. These small dipoles facilitate a linked charge on the surfaces of material, shown with red and blue stright lines. [3]

Herein, the elementary discoveries point out the piezoelectric generation process as shown on Fig. 1, 2, 3 .

\section{B. Material Formations}

The early discoveries were upon natural materials' piezoelectricity effects and specialties. Today artificial compounds are experimented through the combinations of natural piezoelectric materials; such as ceramic based, metal based or plastic based compounds. [2], [4], [5] However, these are the concern of electro-chemical and physico-chemical disciplines. Therefore, we focused on ontological formation of the materials to remain within the frame of our subject that explains spatial purpose use and constructive requirements.

Different application ambients and purported functions require different physical properties in construction materials usually. This principle prevails for energy harvesters, as well. For eg. More flexible materials for indoor finishing, or harder materials for heavy duty loads, or mechanical assemblies for maintenance ease and inter-changeability; and indeed the overall requirement is related to power generation capacity.

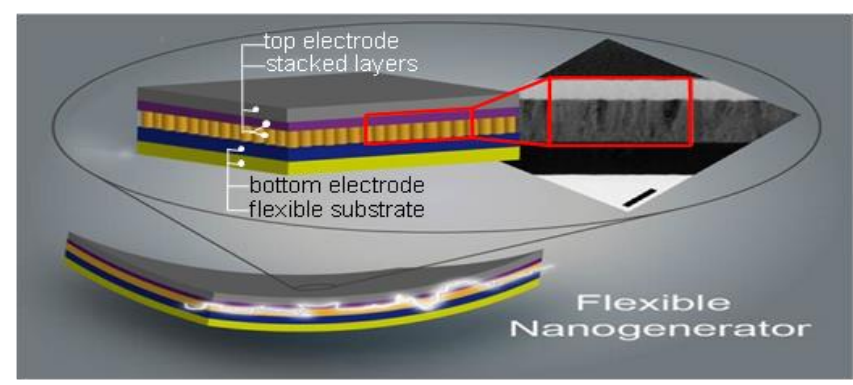

Fig. 4. A flexible laminated type piezoelectric tile. Looks proper to use as indoor floor finishing. (The image in red frame is the natural view of section). [6]

In Fig. 4, the lamination comprises top electrode, stacked layers between, and bottom electrode laid on a flexible substrate. Hesitated point upon flexible laminated materials in construction, looks to be the top electrode. Because it shall be piezoelectric; and this requirement constrains the assignment of traditional hard finishes like ceramics, marbles, granites or parquets.

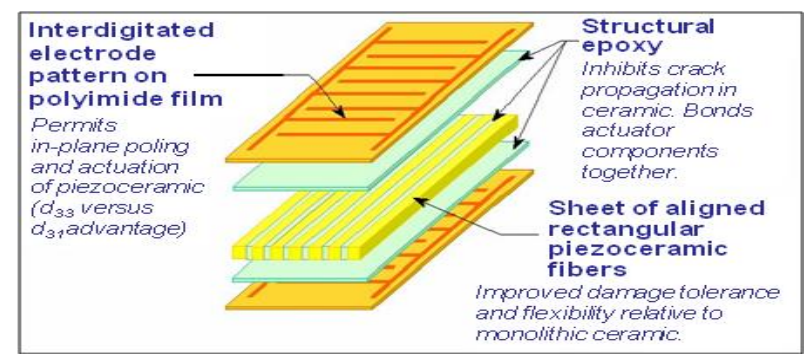

Fig. 5(a). A more harder conditioned for heavy duty usage with its structural strength. [2] 


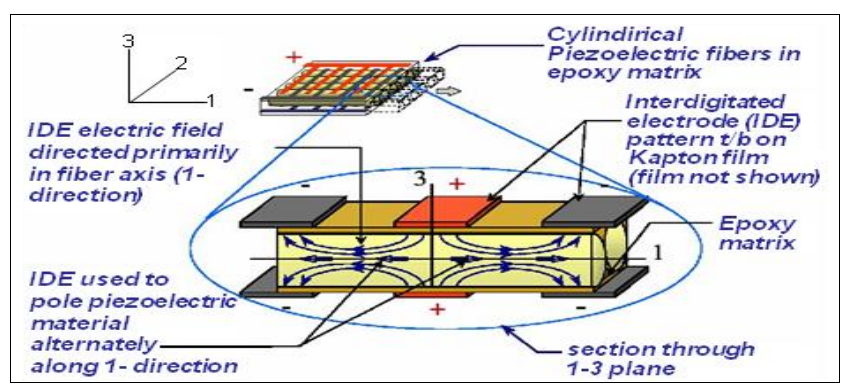

Fig. 5(b). Shows piezoelectric stripes as blow up detail from Fig. 5(a). [2]

The type called "IDE" formation represents a different composition than regular lamination. IDE means "Interdigitated electrode". This formation can generate more energy than other types. However, it needs a heavy load for energy generation. [2], [7]

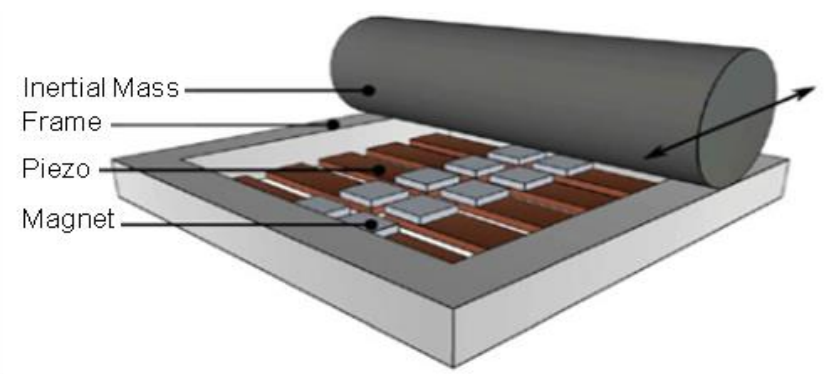

Fig. 6. The mechanical assembly formation is responsive to receive various types of finishes. [4]

In Fig. 6 above, the piezo stripes vibrate when the inertial mass travels on frame and moves the magnets. [4] This type looks proper for spatial use with sensitive vibration activation when covered by a semi-hard / semi-soft finish.

\section{RESEARCH METHODS}

Today, while the material scale searches continue for construction industry usage, piezoelectric materials and assemblies are used in many sectors, for different purposes.

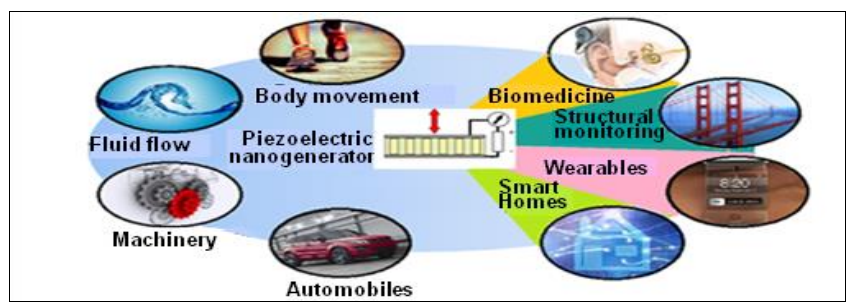

Fig. 7. Well-known usage sectors and areas of piezoelectric materials, also named "piezoelectric nano generators" with applied sources.

According to the graphic design above, in fact, the difference of harvesters, as a construction material, reveals as the installation and fixation methods. When we purport to install, in built and reclamated surfaces, it becomes a construction material. However, the source of energy does not change automobile wheels, machinery vibration, fluid splash, foot step... [4]

\section{A. Basic System Set-out}

When generated energy is harvested by integration of external devices, we will be collecting electrical energy. At this point of view, the design assembly starts as a constructive assembly, as a contract package in design and construction.

In Fig. 8 below, there is a force applied to any piezoelectric material to generate a voltage stress. After we add a collector for storage, and a transducer for re-distribution, the system becomes an energy harvesting and distribution assembly.

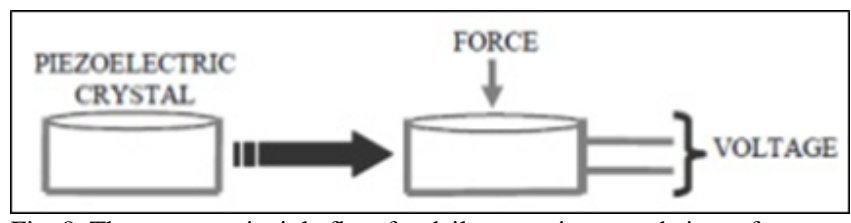

Fig. 8. The system principle flow for daily usage in-around circumferences.

[3]

Subsequently, the stage comes to energy harvesting prediction and estimation by upstream stakeholders, and then aligned design is performed by the electrical engineers of manufacturer, as downstream stakeholder in total project delivery. In fact, the specialist engineers compute prediction upon vibration based on body footsteps. [7]

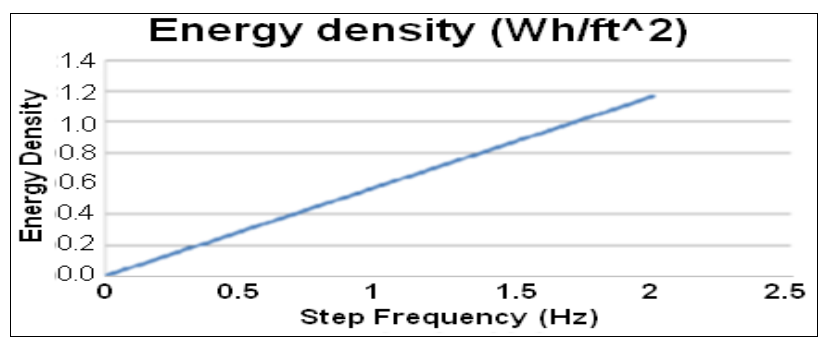

Fig. 9. Energy density on the floor per step frequency in Hertz [7].

However, this method to calculate the energy, can be used by manufacturers' engineers; and remains impractical as a method for construction related engineers and estimation process.

For us it is a more optimized method to use the result of above analyzes, as elementary parameter, for preliminary estimations and requirements, similar to below:

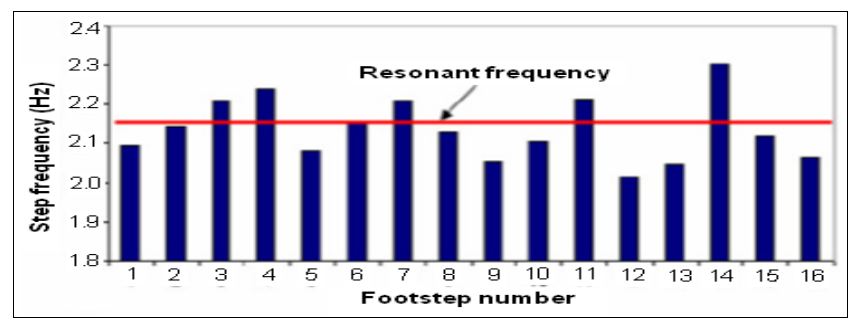

Fig. 10. A basic conversion between footstep numbers and step frequency in Hertz. [8]

Manufacturers provide us the result of unit energy generation responding to 1 footstep, for our project-related calculations and estimations. E.g. 1 footstep generates 6-8 Joules of power. [9]

\section{B. Application Locations}

Indeed, system design can be finalized by determination of applicable location in frame of reasonable parameters. These parameters shall be responsive to purpose and functional abilities of materials and system designation. The parameters are:

- Selection of surfaces, per realistic force fluency prediction.

- Selection of material per generation capacity. 
- Propriety of material per requirements of applied ambient functions.

These parameters prevail throughout all our project management assignment of materials, systems, vendors, etc...

When realistic prediction is aforesaid, first of all the jogging, walking and running activities are the most prominent functions. [3], [4]

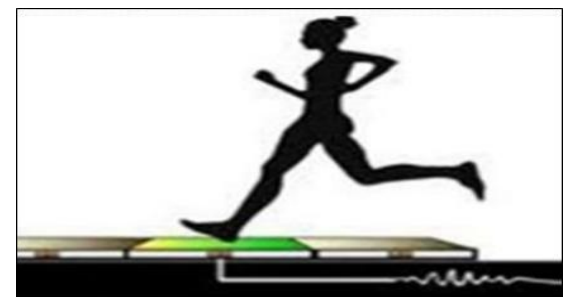

Fig. 11. Running pad tiles can be nano generators, to harvest the energy. [3]

Running pads seem to be optimistic to select, with fluency of footstep and power of each footstep derived during running.

In walking or jogging paths, this time our prediction can be realistic only if there is a high density of people walking / jogging for a period.

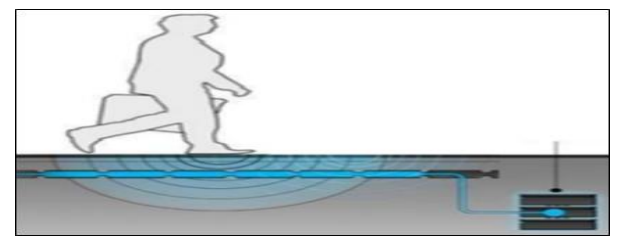

Fig. 12. Walking can provide realistic prediction if there are much people density [3].

A more responsive parameter, to decision method, is provided by sport game fields because of powerful footsteps of 10 to 15 players running in all directions for 1-1.5 hours.

On the other hand, in fact, the most productive parameter and the highest level of energy can be produced from vehicle traffic roads; when the piezoelectric generators are laid under the asphalts. However, the material is under fluent abrasion and open for external effects, like rain. So, in planning and vendor designation, degradation period has to be considered.

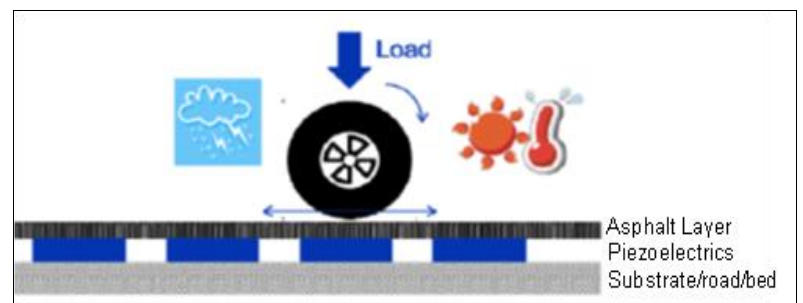

Fig. 13. Under vehicle traffic, piezo cores are directly in-touch with external effects [7].

\section{Method Authentication to Ahmadi}

At the end of the ascertination of requirements, we need to compare the group of application areas with the spaces of Ahmadi Township.

Within these spaces in Ahmadi Town, we found the Sports Ground to have the most fluent prediction upon foot traffic, through game fields and public serving areas in itself.

In the following section, we explain how we calculated our estimation with predictions, to apply the system in Ahmadi
Sports Ground, as a pilot area.

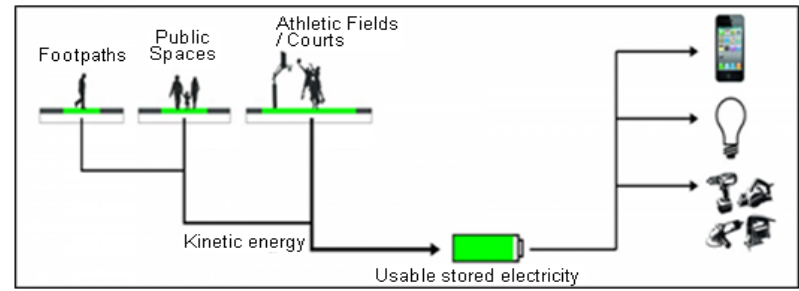

Fig. 14. Ahmadi has rich socio-cultural public places, as determined in decision method. [6]

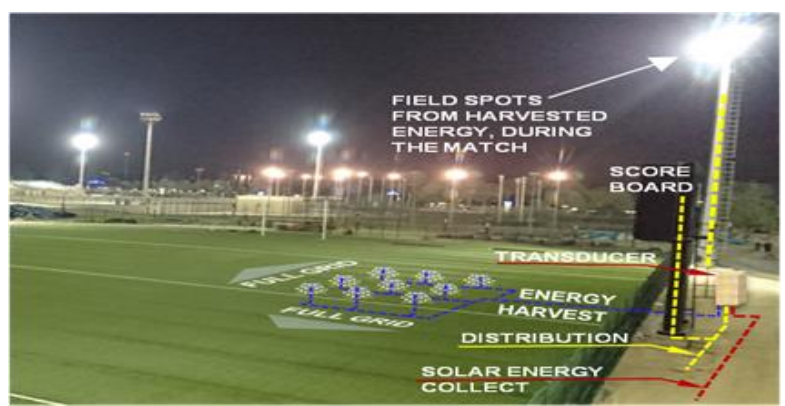

Fig. 15. Facilitation markup of the system for rugby field; scoreboard's \& spots' power come from harvested energy during the matches.

\section{ANALYSIS AND RESUlts}

In the philosophy of Ahmadi Redevelopment Program, there is always an innovative provision, supported by the managerial stakeholders. Accordingly, Ahmadi Redevelopment Program includes innovative provisions as smart city orientation, energy efficiency applications and waste management utilities.

\section{A. Ahmadi Sports Ground}

Since 2006, Ahmadi Town Governorate and KOC accelerates socio-economic investments, not only on housing but also on public places and entertainment areas, to wake up its dynamic history.

In the content of these investment plans, there was also renovation of the Sports Ground, by awaking its popularity similar to 1950s, 1960s and 1970s. In this manner, design of Sports Ground includes attractive content additions, and it facilitates sport activities with family recreations. These additions mean a serious demand and foot traffic in $80.000 \mathrm{~m} 2$ area of the Sports Ground.

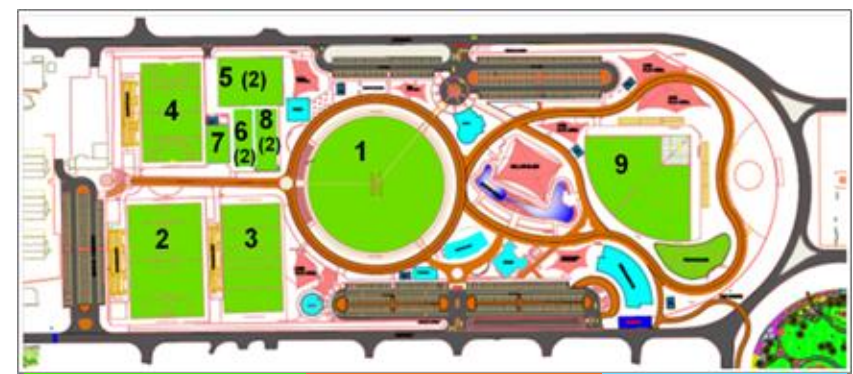

GAME FIELDS WALKWAYS / PATHS PUBLIC BUILDING

Fig. 16. Vicinity plan of Ahmadi sports ground, with walkways, game fields and public places. (Pls. See Fig.-18 for field numbers \& functions).

Jogging paths area is $17.288 \mathrm{~m} 2$ to install the pavement generators. These jogging paths provide energy from footfall of visitors. Visitors load was foreseen as 3500 people for Sports Ground, as density of foot traffic, who are expected to 
have walk on installed pavement generators as marked:

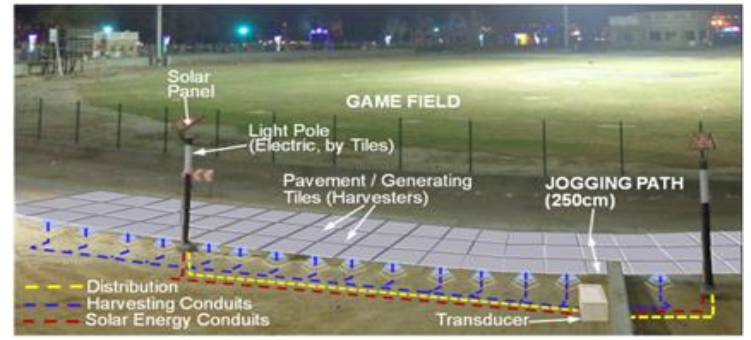

Fig.17. Mock-up and test purpose generator tiling view with designation mark up, at walkways.

We can reach a basic productivity result with the visitors' footsteps, as calculated below:

- 50\% Visitors for a family walk: 1750

-1 tour $=7.000 \mathrm{mt}($ appx.)

- 1 step $=0.75 \mathrm{mt}(75 \mathrm{~cm}$. $)$

- $7.000 \mathrm{mt} / 0.75 \mathrm{mt}=9.333$ steps $/$ person

(In single direction as 1 tour)

-1.750 people jogging $=16.332 .750$ steps

- 1 step generates $6-8$ Joules [6]

- $6 \mathrm{~J}$ x 16.332 .750 steps $>97$ mil. Joules

- 97 mil. Joules $=27$ $\boldsymbol{W h}$ generation.

This reflects one-day energy generation, with the minimum prediction from half of the visitors.

On the other hand, we can calculate the energy that is harvested from Game Fields in Sports Ground, through the prediction of average footsteps during the matches:

\begin{tabular}{|c|c|c|c|c|}
\hline \multicolumn{5}{|c|}{ GAME FIELDS \& PREDICTION PARAMETERS } \\
\hline $\begin{array}{c}\text { GAME FIELDS } \\
\text { (Pls. see Nos. on Fig. } 16 \\
\text { above) }\end{array}$ & $\begin{array}{l}\text { GAME } \\
\text { AREA } \\
\left(\mathbf{m}^{2}\right)\end{array}$ & $\begin{array}{c}\text { STEPS / } \\
\text { MINUTE } \\
\text { (average per } \\
\text { player) }\end{array}$ & $\begin{array}{l}\text { GAME } \\
\text { TIME } \\
\text { (min.) }\end{array}$ & $\begin{array}{l}\text { PLAYER } \\
\text { (2 teams) } \\
\quad(\text { ea. })\end{array}$ \\
\hline 1-CRICKET & 12,695 & 111 & appx.60 & 22 \\
\hline 2-SOCCER & 7,140 & 218 & 90 & 22 \\
\hline 3-RUGBY & 6,400 & 189 & 80 & 30 \\
\hline 4-FIELD HOCKEY & 5,200 & 178 & 50 & 22 \\
\hline 5-MINI SOCCER (2) & 1,400 & 144 PER 1 & 40 & 10 \\
\hline 6-VOLEYBALL (2) & 324 & 232 PER 1 & appx.60 & 12 \\
\hline 7-BASKETBALL (2) & 840 & 230 PER 1 & 40 & 10 \\
\hline 8-CRICKET NETS (2) & 1,440 & 98 PER 1 & \multicolumn{2}{|c|}{ Training only } \\
\hline 9-SOFT / BASEBALL & 8,000 & 111 & appx.60 & 18 \\
\hline TOTAL: & 43,439 & \multicolumn{3}{|c|}{$\begin{array}{l}\text { Total Footsteps per match: } \\
\text { Steps x Time x Players }\end{array}$} \\
\hline
\end{tabular}

Fig. 18. List of games and average footsteps generated at the game fields in sports ground. [10] (Pls. see Fig. 16).

\begin{tabular}{|c|c|c|c|c|}
\hline \multicolumn{5}{|c|}{ WEEKLY PREDICTIONS \& ENERGY } \\
\hline GAME FIELDS & \begin{tabular}{|c} 
Figure-18 \\
PREDICT \\
(per \\
match)
\end{tabular} & \begin{tabular}{|c|} 
MATC \\
H \\
(Weekly \\
)
\end{tabular} & $\begin{array}{c}\text { WEEKLY } \\
\text { PREDICT } \\
\cdot \\
\text { (footsteps) }\end{array}$ & \begin{tabular}{c}
\multicolumn{2}{|c|}{ ENERGY / } \\
WEEK (6 \\
Joules / \\
footstep) \\
\end{tabular} \\
\hline 1-CRICKET & 146,520 & 7 & $1,025,640$ & $6,153,840$ \\
\hline 2-SOCCER & 431,640 & 7 & $3,021,480$ & $18,128,880$ \\
\hline 3-RUGBY & 453,600 & 3 & $1,360,800$ & $8,164,800$ \\
\hline 4-FIELD HOCKEY & 195,800 & 3 & 587,400 & $3,524,400$ \\
\hline 5-MINI SOCCER (2) & 115,200 & 14 & $1,612,800$ & $9,676,800$ \\
\hline 6-VOLEYBALL (2) & 334,080 & 6 & $2,004,480$ & $12,026,880$ \\
\hline 7-BASKETBALL (2) & 184,000 & 14 & $2,576,000$ & $15,456,000$ \\
\hline 8-CRICKET NETS (2) & \multicolumn{4}{|c|}{ Ignored very minor; not applicable } \\
\hline 9-SOFT / BASEBALL & 119,880 & 3 & 359,640 & $2,157,840$ \\
\hline \multicolumn{3}{|c|}{ WEEKLY TOTAL ENERGY } & \multicolumn{2}{|r|}{$75,289,440 \mathrm{~J}}$. \\
\hline
\end{tabular}

Fig. 19. Average energy generated weekly at the game fields in sports ground.

\section{B. Results}

Based on the weather conditions, Kuwait experiences the most favorable period for outdoor activities for around 9 months a year, from September to May. Therefore, we have used 9 months as the parameter, to derive our final result in the below figure:

\begin{tabular}{|r|r|r|}
\hline \multicolumn{2}{|c|}{ SPATIAL PROPORTIONS OF HARVESTING } \\
\hline \multicolumn{1}{|c|}{ SPACES } & WEEKLY & ANNUAL (9 months) \\
\hline SG FIELDS & $20.9 \mathrm{kWh}$ & $752.4 \mathrm{kWh}$ \\
\hline SG WALKWAYS & $189 \mathrm{kWh}$ & $6,804 \mathrm{kWh}$ \\
\hline TOTAL: & $\mathbf{2 0 9 . 9} \mathbf{k W h}$ & $\mathbf{7 5 5 6 , 4} \mathbf{~ k W h}$ \\
\hline
\end{tabular}

Fig. 20. Average power, generated annually in the Sports Ground, based on average footsteps. (Pls. refer to walkways calculation and Fig.19 for fields calculations)

\section{DISCUSSION AND VIEWS}

While we progress in a sustainable redevelopment program in Ahmadi Township, with renewable energy sources, energy efficiency systems, smart orientation and waste management facilities, exploration of piezoelectric nano generators has accelerated our multi-lined echo-friendly sourcing system.

\section{A. Constraints and Risks}

Today there is high productivity and demand in the usage of piezoelectric effect at various industries. However, it has been designated as material in construction industry, just recently.

In construction and related industries, material R\&I works and commercialization process have 2 spatial usages mainly:

- Underlayment for vehicle traffic;

- Pavements for foot traffic.

The usage of piezoelectric effect at foot traffic pavements, is not very prominent, and there are only a few brands that are commercialized by means of serial production, with all components of system package.

In addition, the current power generations remain highly exceptional when compared to average power demands. Therefore, we can highlight that the greatest challenge is the technological and market improvement status, as of options variance, productivity and generated energy level.

On the other hand, the nature of the mechanism depends on users' choice of activity. Accordingly, the highest risk is the accuracy of the level of our predictions. Herein, the risk compensation method is to increase the applied area, under current technological status - in order to gain more profit than non-generating traditional materials.

There is not an enough community of monitoring and control professionals who are specialized on planning, procurement and installation methods of nano generator systems pertaining to construction industry and management. Such condition comes out as a constrain in human resource from managerial view of point.

Concurrently, curious architects, civil engineers and electrical engineers can full-fill this gap as far as they improve and blend the culture with practical applications. Aforesaid material and system cannot be assigned to responsibility of a single discipline; because the system has 
composite properties as finishing material with indigenous energy harvesting grid and constructive requirements.

\section{B. Future Visions}

Considering the amount of energy saved by using the piezoelectric effect in Sports Ground, it was further suggested to apply the generator pavements in construction sites across Ahmadi Township. The below figure shows the Phase-2-2 site, which is our first look ahead.

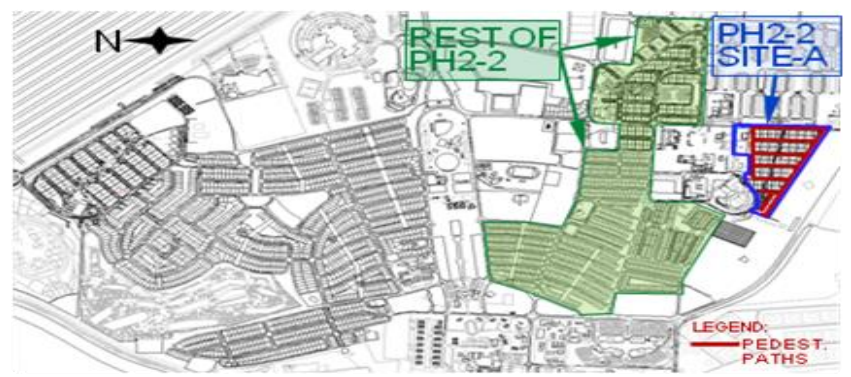

Fig. 21. General master plan of Ahmadi Town, South parts is partially under construction.

There are 3800mt. of pedestrian walkways and 107 houses occupied by minimum 400 inhabitants, in Site-A. We have considered a forecast of 30,396 joules generated per person i.e., by considering only half of the occupiers to be realistic. Subsequently, the plan is to establish the system at pedestrian paths, across all the sites of Phase 2-2 at South Ahmadi, which is approximately 6 times bigger than Site-A with below expectations:

\begin{tabular}{|c|c|c|c|c|}
\hline \multicolumn{5}{|c|}{ HOUSING AREA PEDESTRIAN FOOTSTEPS (DAILY/PERSON) } \\
(1 step=0,75mt) \& (1 step generates 6 joules minimum)
\end{tabular}

Fig. 22(a). 9 months energy generation harvested from applied phases in South Ahmadi.(Ref. to Fig. 21).

\begin{tabular}{|c|c|c|c|}
\hline \multicolumn{4}{|c|}{$\begin{array}{c}\text { TOTAL GENERATION IN SOUTH AHMADI } \\
\text { (1 house daily power demand }=\mathbf{3 0 7} \boldsymbol{k} \text { Wh } \text { average } \text { ) }\end{array}$} \\
\hline PERIOD & ENERGY & POWER & RUNNING USAGE \\
\hline WEEKLY & $>2.842$ bil. Joules & $790 \mathrm{kWh}$ & $2 \mathrm{HOUSES} \mathrm{/} \mathrm{DAY}$ \\
\hline ANNUAL & $>101.5$ bil. Joules & $28,194 \mathrm{kWh}$ & $3 \mathrm{HOUSES} / \mathrm{MONTH}$ \\
\hline
\end{tabular}

Fig. 22(b). Generated energy per person while walking, and then by half of the population of South Ahmadi, for specific periods. (Pls. see Fig. 21).

Power demand of a house is considered as comparison entity, to ease the assumption of amount of energy harvested from foot traffic pavements.

However, the results are realistic enough to run off-grid systems, such as streetlights, scoreboards, field spotlights, Wi-Fi forecast, phone charging machines in a network scale, as well as recommended by miscellaneous manufacturers. [6]

\section{Global Scale Views}

In global scale, still the world attempts to use fossil sources that create pollution, and lead to the depletion of the natural resources. This has not changed for the past 40 years, between 1965 and 2005. [4]
In these 40 years, the first step was to refrain from nuclear facilities, because of several incidents and privative results. In recent years $\mathrm{CO}_{2}$ level was $30 \%$ higher than it was before Industrial Revolution; and added $22 \%$ per decade. [4]

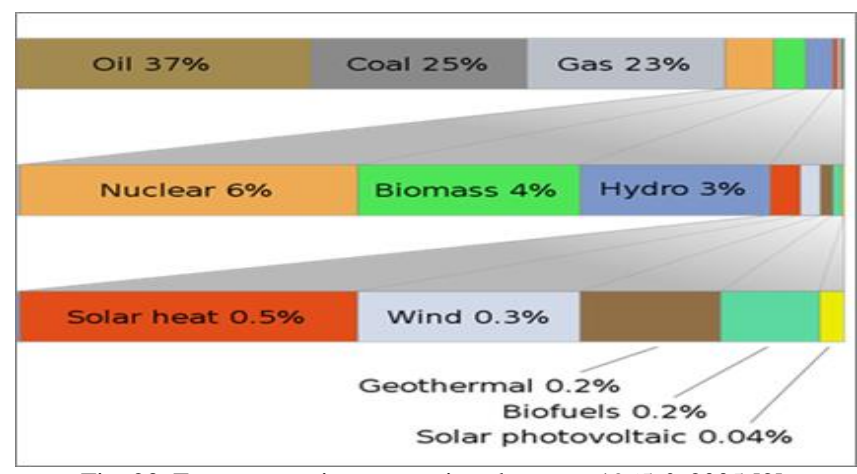

Fig. 23. Energy sourcing proportions between 1965 \& 2005 [2].

When we came to 2015, the energy transmission level has highly accelerated. However, regionally in Middle East \& North Africa, and in Kuwait, there is not a considerable change in sourcing of total energy. Because the research and improvement has just settled; and started to be commercialized, in a minor level.

\begin{tabular}{|c|c|c|c|c|c|c|}
\hline \multicolumn{7}{|c|}{ Sources of Electricity Production } \\
\hline & Coal (\%) & $\begin{array}{c}\text { Natural } \\
\text { Gas (\%) }\end{array}$ & $\begin{array}{c}\text { Oil } \\
(\%)\end{array}$ & $\begin{array}{c}\text { Hydr. pwr. } \\
(\%)\end{array}$ & $\begin{array}{c}\text { Renew. } \\
\text { able } \\
(\%)\end{array}$ & $\begin{array}{c}\text { Nuclear } \\
(\%)\end{array}$ \\
\hline Kuwait & 0.0 & 36.4 & 63.6 & 0.0 & 0.0 & 0.0 \\
\hline MENA & 3.2 & 67.1 & 18.6 & 2.3 & 0.5 & 0.3 \\
\hline World & 39.2 & 22.8 & 3.3 & 15.9 & 6.8 & 0.0 \\
\hline
\end{tabular}

Fig. 24. Energy source proportion, in total energy sources, as per specific regions. [11]

For this reason, in regional view, Ahmadi Town progresses towards a prominent contribution to renewable energy transmission.

\section{CONCLUSION AND ACHIEVEMENTS}

Kuwait Oil Company, the investor of Ahmadi Redevelopment Program, has opened the way for innovation by planning and application of nano generators system as a renewable energy source. This decision puts forward outcomes as explorations, how-to-know and learnt lessons records that facilitate start points of further improvements.

\section{A. Achievements}

Ahmadi Town became the first area in Kuwait with renewable energy usage in network and community scales.

Single usage of nano generators reduced energy cost and source spending, in minor level as a starting stage.

There are clear parameters explored anymore, to select the right material option, to determine the feasible spaces and to filter the initial technology updates.

In line with the above achievement, there is a ready program monitoring team specialized to apply parameters, to plan, deliver, monitor and to control the system application, with their knowledge and culture which is more than simply fundamental.

In this manner, record folders are active for lessons learnt 
and the best practice applications.

\section{B. Recommendations}

In Ahmadi Town scale, a hybrid-automated system with integration of piezoelectric harvesters, solar panels and wind sources, will reduce energy expenditures of The Town considerably.

Herein, the subsequent stage would be the harvester underlayment below peripheral roads of Ahmadi Town that provides huge energy harvesting, in comparison with foot traffic pavement generators.

In this manner, Ahmadi Town objects to be one of the most prominent energy efficiency communities in the area, although it is the capital of Oil in Kuwait.

\section{CONFLICT OF INTEREST STATEMENT}

We clearly and kindly declare that the submitted paper was carried out without any conflict of interest.

\section{AUTHOR CONTRIBUTIONS}

Below are the Author's contributors.

Ahmed Khalil - TPL Specialist Engineering (KOC): The Author

Koray Pekingor, Eng. Architect and Heba El-Baroudi,, Electrical Eng.: Analysis for services requirements and evaluate/ compare data.

\section{REFERENCES}

[1] Wikipedia keywords "Piezoelectricity"/“Pyroelectricity" / "Gabriel Lippman" / "Jaques Curies"/ "Pierre Curie".

[2] I. Patel, "Chapter-8: Ceramic based piezoelectric energy harvesting device," Advances in Ceramics Electric and Magnetic Ceramics, Bioceramics, Ceramics and Environment, 2011, ch. 8, pp. 133-154.

[3] M. J. A. Khan, V. N. Raju, and T. P. Karthik, "Piezoelectric based energy harvesting," MS Ramaiah School of Advanced Studies, Coventry Univ. , UK, 2012

[4] L. B. Kong, T. Li, H. H. Hong, F. Boey, T. Zhang, and S. Li, Waste Energy Harvesting: Mechanical and Thermal Energies, Berlin: Springer-Verlag, 2014, pp. 15-31.

[5] E. Lee, J. Park, M. Yim, Y. Kim, and G. Yoon, "Zinc oxide materials tapped for tiny energy harvesting devices," Journal Applied Physics Letters by American Institute of Physics, 2016.
[6] Eagleman, Kinetic Tiles and The Inventor, Word Press, February 2015.

[7] D. Hill and N. Tong, "Assessment of piezoelectric materials for roadway energy harvesting," prepared for California Energy Commission, as contribution to Energy Research and Dev.'ment Division's Energy Systems Integration Program, California, CA January, 2014

[8] N. Lythgo and E. Gad, "Evaluation of footfall induced vibration in building floor," presented at Australian Earthquake Engineering Society Conference, Barossa Valley, South Australia, p. 7, ch. 4, 2011.

[9] L. Kemball-Cook, "The pavement that generates electricity: Getting an invention to market," The Guardian, December 2012.

[10] Step Conversion Charts Miscellaneous. [Online]. Available: www.takesteps.univerahealthcare.com

[11] The World Bank, World Development Indicators: Electricity Production, Sources of Electricity Production.

Copyright $\odot 2020$ by the authors. This is an open access article distributed under the Creative Commons Attribution License which permits unrestricted use, distribution, and reproduction in any medium, provided the original work is properly cited (CC BY 4.0).

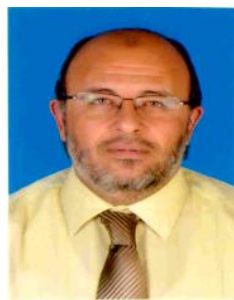

A. Khalil holds a master's degree from Ain Shams University of Egypt, Cairo, Egypt in civil engineering (structure)

$\mathrm{He}$ is a TPL- SPECIALIST working for Kuwait Oil Company (KOC), Ahmadi, Kuwait for the past 24 years and has extensive experience in the managing multi-million dollar projects with a very good record of accomplishment during his 32 years career in the construction industry in the Middle East Region.

He has presented at many conferences in the Middle and Far East regions and written papers for the external and Company's publications including International Journal of Innovation, Management and Technology, Vol. 10 No. 1, Feb 2019, International Journal of Engineering and Technology, Vol. 10, No. 3, June 2018, Conference proceedings at the 4th International Conference on Renewable Energy Technologies and International Conference on Sustainability, Green Buildings, and Environmental Engineering \& Renewable Energy.

Mr. Ahmed Khalil's contributions include participation in the Company's various committees, Task forces for special projects and assignments such as the Ahmadi Gas project Task Force that successfully mitigated the gas emissions in the township of Ahmadi, Rebuilding Ahmadi Township Steering Committee and Technical Task Force; and many other investigation committees including the Directorate representative for the State Audit Bureau. He also has major contributions in developing and enhancing the quality and standard procedures, such as the quality management system manual, business operating procedures for the company as well as enhancing the company standards. 